Recepción: 12 / 05 / 2018

Aceptación: 23 / 07 / 2018

Publicación: 15 / 09 / 2018

Ciencias económicas y empresariales

Artículo de investigación

\title{
Inversión extranjera directa sector manufacturero e industrial en América
}

\section{Latina}

Foreign direct investment manufacturing and industrial sector in Latin America

Fabricação de investimento directo estrangeiro e setor industrial na América

\section{Latina}

\author{
Manuel N. Calderón-Sánchez ${ }^{\mathrm{I}}$ \\ neptalicalderonsmed@gmail.com \\ Rosa B. Calle-Oleas II \\ rosa.calle@unl.edu.ec \\ Jorge H. Moncayo-Flores ${ }^{\text {III }}$ \\ jorge.mflores@unl.edu.ec
}

\section{Correspondencia: neptalicalderonsmed@gmail.com}

\footnotetext{
${ }^{I}$ Magister en Administración de Empresas, Servidor Administrativo de la Facultad Jurídica, Social y Administrativa de la Universidad Nacional de Loja, Loja, Ecuador.

II Magister en Gerencia Contable Financiera, Docente de la Facultad Jurídica, Social y Administrativa de la Universidad Nacional de Loja. Loja, Ecuador.

III Magister en Derecho Administrativo, Docente de la Facultad Jurídica, Social y Administrativa de la Universidad Nacional de Loja, Loja, Ecuador.
} 


\title{
Resumen
}

El presente artículo analizó los comportamientos económicos surgidos por la inversión extranjera en el sector Manufacturero de América Latina, se visualiza los cambios estructurales, comparación de taxonomías y la evolución de la estructura industrial de los años 1970 - 2003 de la edición del Proyecto CAPAL; además, las cuatro fases bajo el sistema de BRETTON WOODS, desde la crisis petrolera hasta el retorno de los capitales. Se caracteriza los contextos de algunos países en el sector Manufacturero como Guatemala 2002 - 2012, Colombia 1970 - 2009, México1994 - 2008 y Chile 1990- 2000; se establece porcentajes de la participación de las distintas ramas de la actividad económica que aportaron al PIB, flujos de inversiones y producción por sectores. La inversión extranjera directa en América Latina y el Caribe 2013, 2015, 2016 documento informativo.

Palabras claves: inversión extranjera directa (ied); up manufactura; desarrollo industrial; crecimiento; taxonomía.

\begin{abstract}
This article economic behavior arising from foreign investment in the Manufacturing sector in Latin America is analyzed, structural changes visualized, compared taxonomy and evolution of industrial structure from the years 1970 - 2003 edition of CAPAL Project; besides the four phases under the Bretton Woods system, since the oil crisis until the return of capital. 2012, Colombia 1970 - - 2009, México1994 - 2008 and Chile 1990 - the contexts of some countries in the Manufacturing sector Guatemala 2002 is characterized 2000, percentages of participation of the different branches of economic activity was established as contributed to GDP investment flows and production sectors. Foreign direct investment in Latin America and the Caribbean 2013, 2015, 2016 information document.
\end{abstract}

Keywords: investimento estrangeiro direto (ied); fabricação; desenvolvimento industrial; crescimento; taxonomia. 


\section{Resumo}

Este artigo analisou os comportamentos econômicos decorrentes do investimento estrangeiro no setor manufatureiro na América Latina, visualiza as mudanças estruturais, a comparação de taxonomias e a evolução da estrutura industrial dos anos 1970 a 2003 da edição do Projeto CAPAL; além disso, as quatro fases do sistema BRETTON WOODS, desde a crise do petróleo até o retorno do capital. Os contextos de alguns países do setor Manufatureiro são caracterizados, como Guatemala 2002 - 2012, Colômbia 1970 - 2009, México 1994 - 2008 e Chile 1990 - 2000; percentuais da participação dos diferentes ramos de atividade econômica que contribuíram para o PIB, fluxos de investimento e produção por setor são estabelecidos. Investimento direto estrangeiro na América Latina e Caribe 2013, 2015, 2016 documento informativo.

Palavras chave: investimento direto estrangeiro (ied); fabricação; desenvolvimento industrial; crescimento; taxonomia.

\section{Introducción}

El articulo permite visualizar los cambios surgidos en la industria Manufacturera e Industrial en América Latina, considerando la información bibliográfica recopilada para la construcción de este documento, se consideró el artículo de la CEPAL (1970 -2003); en este periodo se evidenciaron cambios estructurales, taxonomías de sectores de la industria y la evolución industrial; se establecen 4 fases bajo el sistema de BRETTON WOODS, la primera comprende los años 1970 - 1973, la segunda los años 1974 - 1981, la tercera los años 1983 - 1990 y la cuarta de 1991 - 2000. En la primera se considera la crisis petrolera y el colapso del sistema monetario basados en los tipos de cambio surgidos en aquella época, la segunda se caracterizó por un bajo dinamismo de las economías desarrolladas y una alta liquidez mundial, se basó en los llamados petrodólares generados por la banca privada internacional, la cual causó el endeudamiento y crisis de 1982, la tercera es la década de pérdida, debido a los ajustes destinados a deuda pública y la cuarta que marco el retorno de los capitales externos y la implementación de reformas estructurales como la liberación del comercio. 
Se analiza el contexto del sector manufacturero de Guatemala 2002 - 2012, mismo que representó el 18.3\% de los 11 sectores que aportan al PIB en el tercer trimestre del 2012. El sector Manufacturero de Colombia se ha considerado el sector más importante al interior de los países por sus avances tecnológicos. Además, el contexto de la integración de México sector manufacturero 1994 - 2008, juega un papel central en las relaciones económicas entre México y EUA, se estudia el desarrollo de la Industria Manufacturera Chilena 1990 - 2000 que experimentó un crecimiento promedio anual de un 5\%, el PIB disminuyó de un 18.7\% en 1990 a un $16.1 \%$ en el 2000 , esto influyó en la economía del país. Estos antecedentes permiten evidenciar algunas caracterizaciones de la inversión extranjera en el sector manufacturero de América Latina y el Caribe.

\section{Metodología}

El desarrollo del presente artículo denominado Inversión Extranjera Directa Sector Manufacturero e Industrial en América Latina se realizó, utilizando bibliografía de varios artículos de la CEPAL, que permitieron visualizar el comportamiento del cambio estructural manufacturero desde los años 1970. La recolección de los datos se realizó en la fuente de datos que se encuentra en los, informes de CEPAL, principalmente, y otras entidades como los últimos cálculos realizados por United Nations industrial Depelopment Organization - UNIDO, estos facilitaron un leve vistazo de las competencias sectoriales de los países de América del Sur, con ello se enriqueció el análisis y discusión de las tendencias que determinan la inversión extranjera.

\section{Resultados}

\section{Desarrollo productivo en la industria manufacturera y crecimiento económico}

La Comisión Económica para América Latina y el Caribe, a través de su edición y publicación del proyecto (CEPAL), Centro Internacional de Investigaciones para el Desarrollo (IDRC, Canadá) sobre Restructuración Industrial y Competitividad Internacional en América Latina y el Caribe (CAN 97/025), es el organismo dependiente de la Organización de las Naciones Unidas responsable de promover el desarrollo económico y social de la región. 
El artículo muestra el cambio estructural en la Industria manufacturera en América Latina desde los años 70 en adelante especialmente en la productividad, competitividad y crecimiento; se comparan las taxonomías de sectores industriales con el fin de construir indicadores de intensidad tecnológica de la estructura productiva y se hace un análisis de la evolución de la estructura industrial de algunos países entre los períodos 1970 y 2003. En este periodo se divide las fases de: crecimiento con endeudamiento en los años 70; década perdida en los años 80; período de reformas y retorno de los capitales externos en los años 90, y el ciclo moderado de crecimiento que inicia junto al siglo XXI.

Desde los años ochenta la industria latinoamericana ha tendido a concentrarse en sectores menos dinámicos desde el punto de vista tecnológico lo que ha reflejado negativamente en su productividad en relación a la de EE.UU; la siguiente sección se traslada en la dimensión sectorial a una reflexión sobre el crecimiento a largo plazo basada en una comparación del desempeño latinoamericano, presenta dos tipologías de países, los basados en indicadores de estructura y en variables geográficas y especialización; manifiesta que América Latina está en el grupo que presenta los indicadores de capacidad tecnológica menos favorables.

\section{Indicadores de la estructura productiva, intensidad tecnológica y especialización}

Estos grupos se establecen en función del factor de producción usado más intensivamente como recursos naturales, trabajo y tecnología, en la clasificación de la CEPAL los sectores ING son los más intensivos en conocimiento, coinciden en ellas los sectores intensivos en tecnología en el cuadro se comparan tres taxonomías. 


\section{Cuadro Nro. 1}

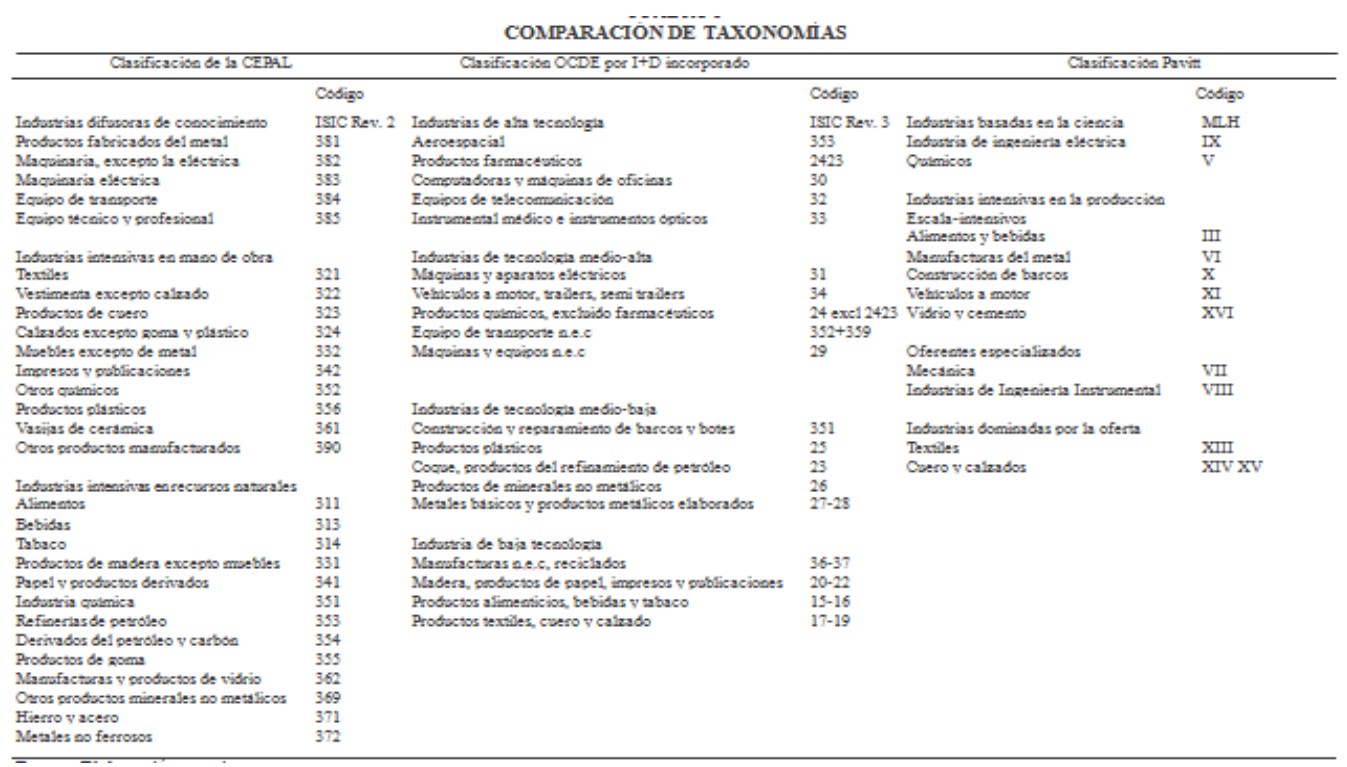

De acuerdo a la clasificación de la Organización para la Cooperación y el Desarrollo Económicos (OCDE) propuesta por Hatzichronoglou en 1997, estudio efectuado en 10 países que eran miembros de la Organización para los años 80 y 90. La construcción de este ordenamiento se usó la Clasificación Industrial Internacional Uniforme de todas las actividades económicas (CIIU), en donde se identificó cuatro sectores de acuerdo a la intensidad tecnológica: Alta tecnología, mediana - alta tecnología, mediana - baja tecnología y por último baja tecnología.

En base a la clasificación de sectores industriales de la CIIU, Rev. (OCDE, 2005), el estudio comprende 1991 - 1999 y se incluyeron 12 países como Canadá, Estados Unidos, Japón, Alemania, Dinamarca, España, Finlandia, Francia, Irlanda, Italia, Suecia y Reino Unido, se emplearon únicamente dos indicadores el gasto en $\mathrm{I}+\mathrm{D}$ como proporción del valor agregado y como proporción de la producción.

Al existir varias taxonomías en donde se destaca el artículo de Pavitt en 1984, describe patrones sectoriales de cambios tecnológicos en la Industria manufacturera británica, este estudio comprende de 1945 - 1979 y se basa en los registros de más de 2000 innovaciones significativas; los sectores son alimentos, bebidas, químicos, manufacturas del metal; ingeniería mecánica, instrumental, eléctrica y electrónica; construcción de barcos, vehículos, textiles, cuero y calzado, cerámica, vidrios, vasijas, etc. 


\section{Cuadro Nro.2}

\section{RELACION ENTRE GASTO EN I+D Y PRODUCCION PARA EL TOTAL DE LOS PAISES DE LA OCDE,1991-1999}

\begin{tabular}{lc}
\hline Industrias & Producto \\
\hline Industrias de alta tecnología & 9,3 \\
Aeroespacial & 13,3 \\
Productos farmacéuticos & 10,5 \\
Computadoras y máquinas de oficina & 9,2 \\
Equipos de telecomunicación & 8,0 \\
Instrumental médico e instrumentos ópticos & 7,7 \\
& \\
Industrias de tecnología medio-alta & 3,0 \\
Máquinas y aparatos eléctricos & 3,9 \\
Vehículos a motor, trailers, semitrailers & 3,5 \\
Productos químicos, excluido farmacéuticos & 3,1 \\
Equipo de transporte n.e.c & 2,9 \\
Máquinas y equipos n.e.c & 2,1 \\
& \\
Industrias de tecnología medio-baja & 0,8 \\
Construcción y reparamiento de barcos y botes & 1,0 \\
Productos plásticos & 0,9 \\
Coque, productos del refinamiento de petróleo & 0,9 \\
Productos de minerales no metálicos & 0,9 \\
Metales básicos y productos metálicos elaborados & 0,6 \\
Industria de baja tecnología & 0,3 \\
Manufacturas n.e.c, reciclados & 0,5 \\
Madera, productos de papel, impresos y publicaciones & 0,3 \\
Productos alimenticios, bebidas y tabaco & 0,3 \\
Productos textiles, cuero y calzado & 0,3 \\
\hline
\end{tabular}

Fuente: Organización de Cooperación y Desarrollo Económicos (OCDE), Science, Technology and Industry Scoreboard 2005, Anexo A, París

Keith Pavitt agrupa los sectores industriales en tres grandes categorías: los "dominados por la oferta", los "intensivos en producción", dentro de los que se distingue entre industrias "intensivas en escala" y "oferentes especializados"; y, por último, aquellos "basados en la ciencia".

Pavitt, muestra claramente que los sectores en los cuales la tecnología tiene mayor incidencia son aquellos basados en la ciencia y los oferentes especializados, entre los que incluye la química, la electrónica, las industrias dedicadas a la producción de distintos instrumentos y la mecánica. Se 
establece que existe convergencia entre las taxonomías en la clasificación de las industrias a partir de su intensidad tecnológica.

Cuadro Nro. 3

\begin{tabular}{|l|l|}
\hline \multicolumn{2}{|c|}{$\begin{array}{l}\text { PARTICIPACIÓN DE LOS SUBSECTORES EN LOS EN LAS INNOVACIONES } \\
\text { TOTALES DEL SECTOR MANUFACTUREROS }\end{array}$} \\
\hline Subsectores & Porcentajes \\
\hline Textiles & 4,0 \\
\hline Cuero y Calzados & 1,5 \\
\hline & \\
\hline Alimentos & 2.9 \\
\hline Manufacturas del Metal & 6,0 \\
\hline Construcción de Barcos & 2,3 \\
\hline Vehículos a motor & 5,7 \\
\hline Vidrio y Cemento & 3.2 \\
\hline & \\
\hline Ingeniería mecánica & 27,9 \\
\hline Instrumentos & 14,7 \\
\hline change: towards a taxonomy and a theory", Research Policy, vol.13,1984 \\
\hline Industria Química & 11,1 \\
\hline Otras firmas & 5,8 \\
\hline Total & 100,00 \\
\hline Fuente de elaboración propia sobre la base & \\
\hline
\end{tabular}

La participación del grupo ING en el valor agregado de la industria manufacturera mantiene una alta correlación con la capacidad de la estructura productiva para generar conocimientos, producir 
externalidades y competir internacionalmente sobre bases tecnológicas y no solo a partir de la dotación original de factores.

\section{Evolución de la estructura de la industria manufacturera}

(PADIWIN) de la CEPAL, examina los indicadores de estructura industrial en un grupo de economías latinoamericanas entre 1970 y 2003. El período se divide en cinco fases, definidas a partir de alteraciones significativas del contexto externo e interno que afectaron al conjunto de América Latina.

Con el método de Bretton Woods La primera fase, 1970-1973, marca el fin del período áureo de crecimiento de la economía y el comercio internacionales. La primera crisis del petróleo y el colapso del sistema monetario basado en tipos de cambio fijos cierran esta fase. La segunda entre 1974 y 1981, se caracteriza por un bajo dinamismo de las economías. Muchas economías de la región crecen en ese momento sobre la base del endeudamiento, lo que prepara el terreno para la crisis de la deuda de 1982. La tercera entre 1982-1990, es la década perdida; y, la cuarta entre 1991 y 2000, que marcan el retorno de los capitales externos y la implementación de las reformas estructurales, y el período que se inicia el año 2000 con la expansión de la economía internacional y del peso creciente de las economías asiáticas en el comercio, fenómenos que revitalizan la demanda de productos primarios.

\section{Industria manufacturera 2012}

Los cambios de América Latina y el Caribe en materia de inversión extranjera en el sector Manufacturero e Industrial, se analizó información bibliográfica, los últimos cálculos realizados por United Nations industrial Depelopment Organization - UNIDO - el crecimiento global fue bajo en el tercer trimestre de 2012, por la recesión económica en Europa y su impacto cada vez mayor sobre las nuevas economías industrializadas y en desarrollo. Según las estimaciones de la - UNIDO - la producción manufacturera mundial creció apenas un 2.2\% en el tercer trimestre de 2012, en comparación al del año anterior. Esta es la tasa más baja de crecimiento desde el último trimestre de 2009. El sector ha caído un 1.3\% en comparación con el trimestre anterior, lo que muestra el debilitamiento de la economía mundial. 


\section{Grafico Nro. 1}

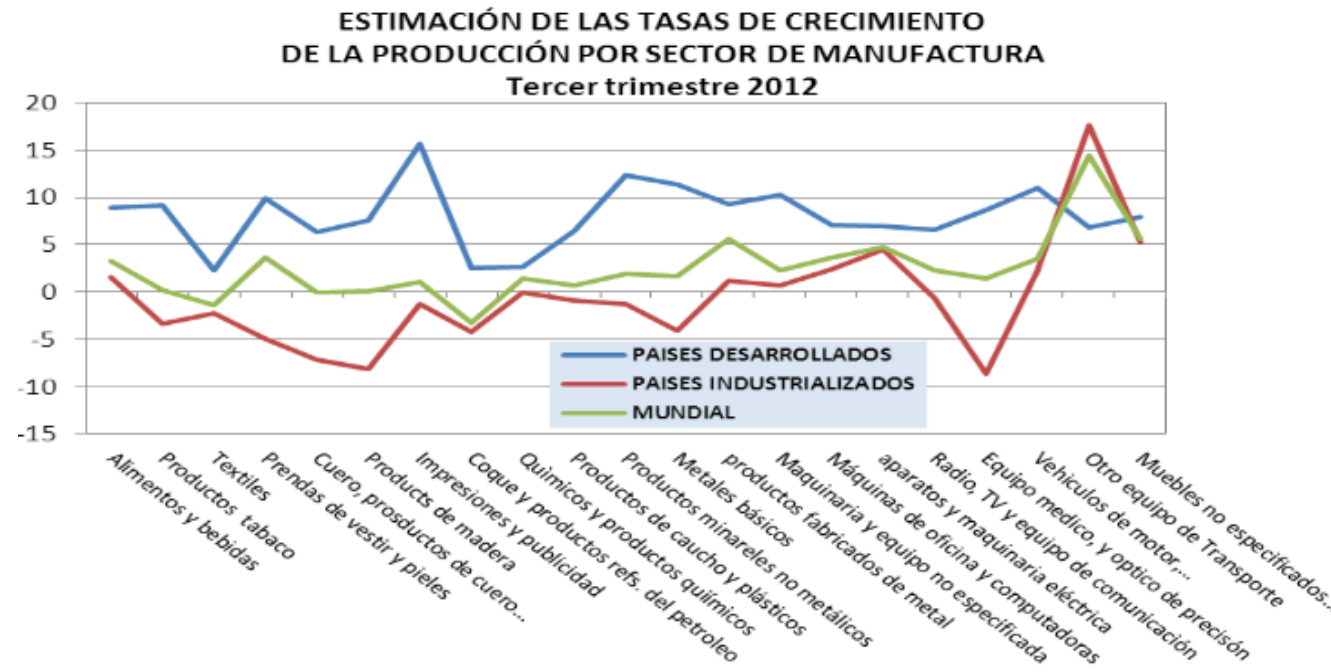

Fuente: UNIDO

\section{Caracterización del sector}

LA OCDE y la CEPAL, identifican tres grupos de países: Los del Cono Sur; los de Centroamérica, y, grupo conformado por Costa Rica, Brasil y México, que presentan el mayor grado de diversificación regional en las exportaciones incluyendo manufacturas.

América Latina, la manufactura de Brasil cayó por tercer trimestre consecutivo en 2012, la producción de maquinaria y equipo y vehículos de motor se redujo en el tercer trimestre. La manufactura cayó también en Argentina y Colombia, sin embargo, Chile, México y Perú tuvieron una mayor tasa de crecimiento de esta producción en más de un 4.0\%. Mostro un crecimiento en el primer semestre del 2012 en América del Norte y Asia Oriental y cierta incertidumbre en Europa.

El sector que muestra un impulso es el de vehículos en donde los EE.UU presentan un fuerte crecimiento, así como en Canadá y el Reino Unido; en contraste la fabricación de automóviles de Japón experimentó un fuerte descenso debido a la disminución de exportaciones, especialmente a China.

\section{Contexto internacional del sector y del mercado}

UNIDO, revela la recesión en Europa, la disminuida recuperación en América del Norte y la baja producción en el Este de Asia. Como efecto en los países industrializados la producción manufacturera total cayó un $0.3 \%$ en comparación con el año anterior, es la primera vez desde el último trimestre de 2009 que el crecimiento promedio de todos los países industrializados ha sido 
negativo; las manufacturas fueron el recurso clave del crecimiento económico y la recuperación de la crisis financiera tanto para EE.UU como para Japón. Dadas las condiciones del crecimiento en el sector manufacturero, la forma de comprobar su comportamiento es a través del Purchasing Manager Index, indicador similar al del PIB, en donde el nivel en condiciones de expansión económica debe estar por encima de 50.0\% Dicho indicador, cerró en diciembre de 2012 manifestando cierta contracción al situarse en un nivel de $46.1 \%$, en donde en febrero alcanzó su punto máximo en el 2012, 49.0\%. Cabe mencionar que desde agosto de 2011 este indicador se extendió hasta su décimo séptimo mes consecutivo por debajo del límite anteriormente indicado, con lo que se observan pocas expectativas de crecimiento en la Eurozona e impactando otras variables como el empleo.

Gráfico Nro. 2

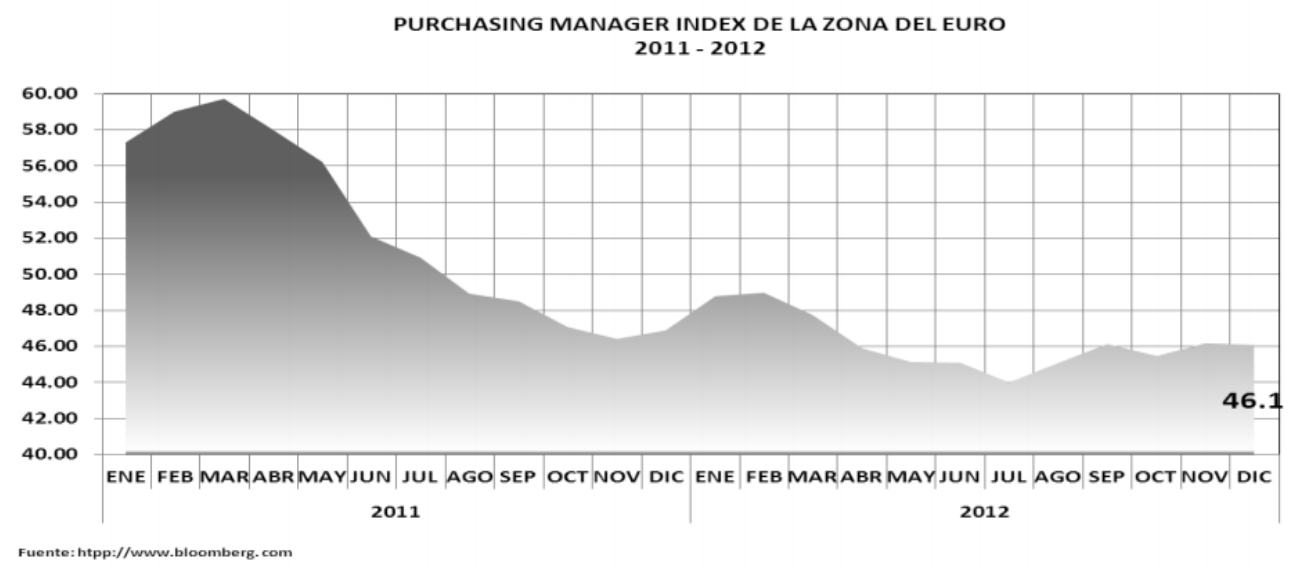

\section{Es de indicar que este dato es congruente con los análisis de la - UNIDO}

\section{Gráfico Nro. 3}

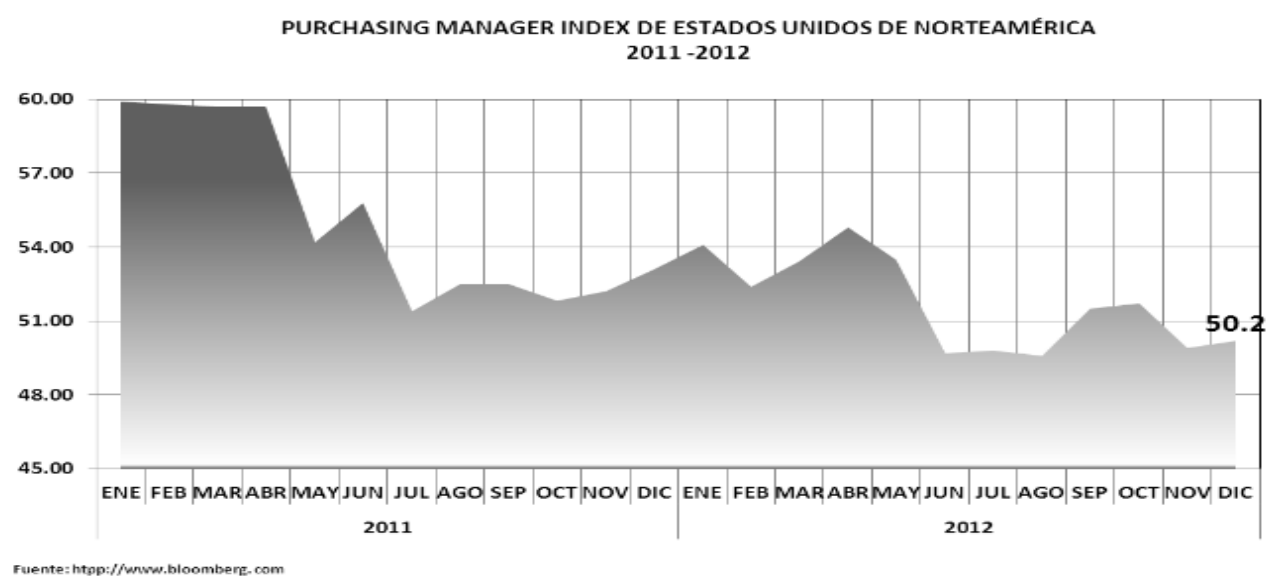




\section{Contexto nacional del sector y del mercado}

En Guatemala la manufactura y ensamble, el Ministerio de Economía informa que en su mayoría lo conformó industrias relacionadas con vestuario y textiles y su objetivo es posicionar a Guatemala como destino de inversión de clase mundial, atractivo para empresas del sector manufacturero de alto valor agregado, desarrollando subsectores estratégicos como: electrónicos, autopartes y dispositivos médicos; y, sus socios comerciales son: Centroamérica, USA, México, Caribe, Sudamérica, Unión Europea; este sector manufacturero representó el 18.3\% de los 11 sectores que aportan al PIB para el tercer trimestre del 2012; y, en cuanto a la variación interanual de dicho sector, el tercer trimestre de 2012 con respecto el tercer trimestre de 2011, fue de 3.6\% (utilizando año base 2001).

Grafico Nro. 4

Industrias manufactureras

PERÍODO 1T-2002 - 3T-2012

Tasas de variación Interanual

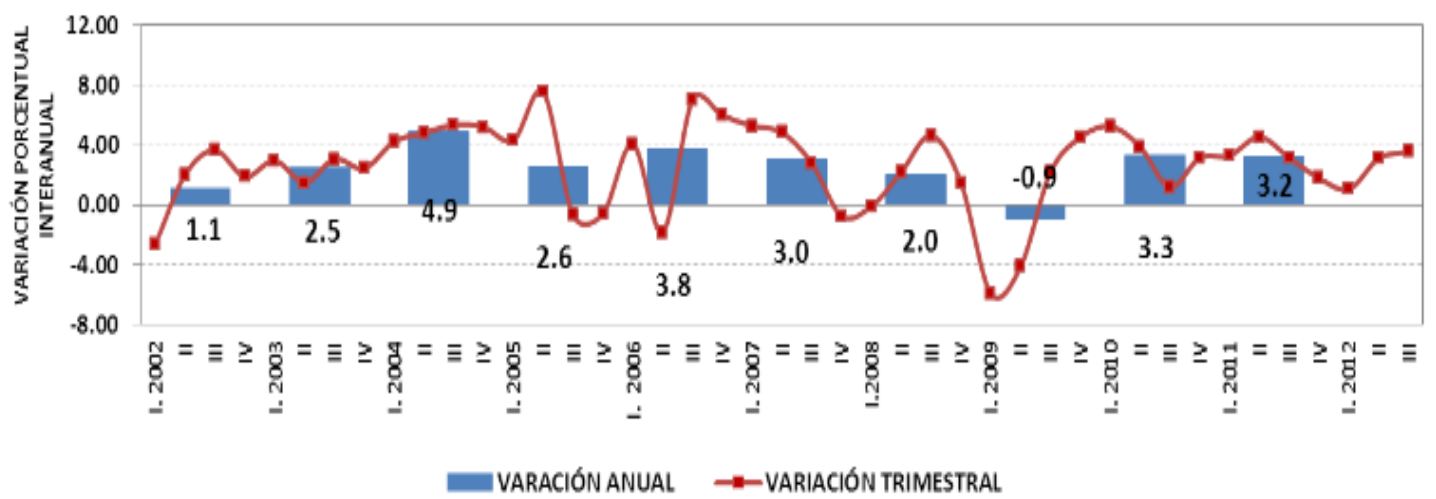

Fuente: Banguat

Los créditos de bancos, sociedades financieras y entidades fuera de plaza para la industria manufacturera según el informe trimestral de la Superintendencia de Bancos ascendieron a Q 15,001.5 millones a diciembre de 2012 , hubo crecimiento del $16.2 \%$ con relación a la misma fecha del año anterior. Con ello, la participación de la cartera de créditos a la industria manufacturera se ubicó en $11.9 \%$.

El incremento registró principalmente cambios en el renglón de productos alimenticios, bebidas y tabaco, que aumentó Q 1,417.5 millones, que explica el 67.6\% de la variación total. También 
importantes renglones referentes a la fabricación de productos metálicos, maquinaria y equipo en Q230.4 millones; de industrias metálicas básicas en Q181.6 millones; y, de textiles, prendas de vestir e industrias de cuero en Q130 .7millones. En contraposición, la cartera para la fabricación de productos minerales no metálicos exceptuando los derivados del petróleo y del carbón se contrajo en Q115.6 millones.

\section{Grafico Nro. 5}

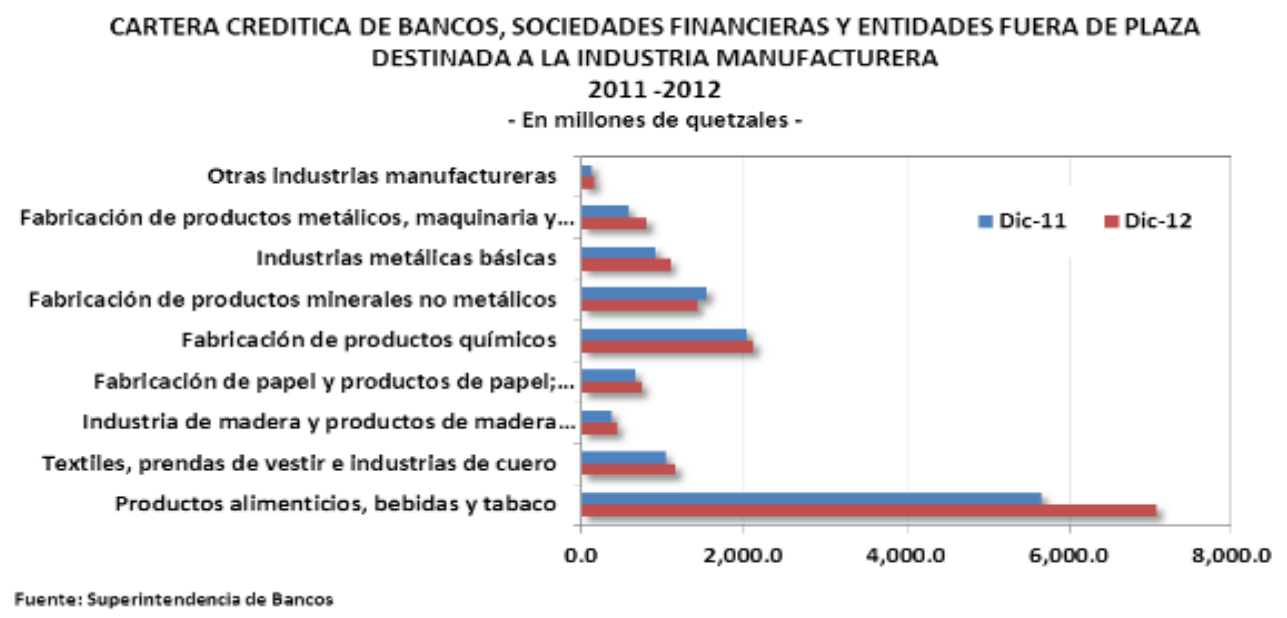

De los Q 15,001.5 millones reportados por la Superintendencia de Bancos a diciembre de 2012 dedicados a la manufactura, lo ocupan la fabricación de alimentos, bebidas y tabaco con el $47.2 \%$, siguiéndole la fabricación de sustancias químicas y de productos químicos derivados del petróleo y del carbón de caucho y plástico con 14.1\%; y la fabricación de productos minerales no metálicos exceptuando los derivados del petróleo y el carbón con el 9,5\%.

\section{Grafico Nro. 6}

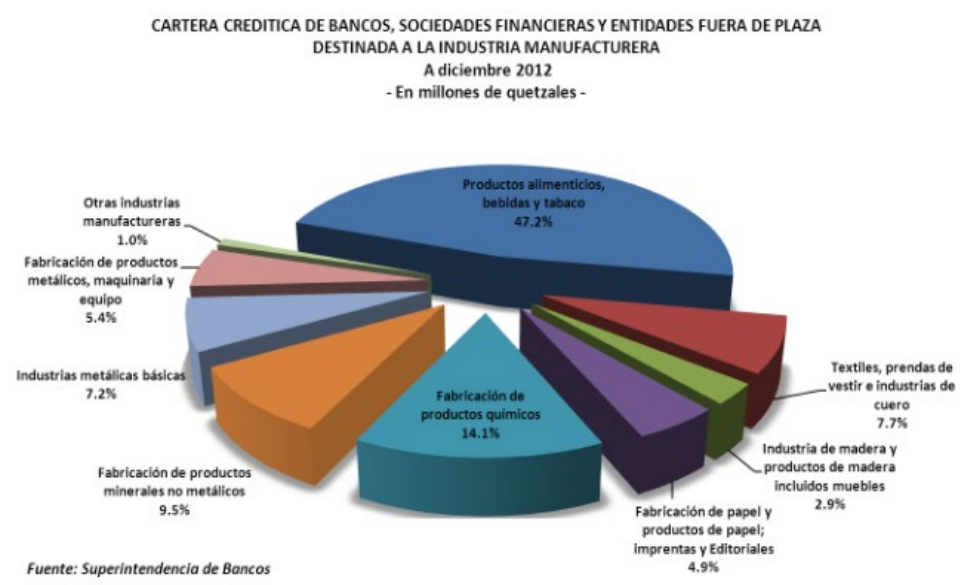




\section{Perspectivas del sector y del mercado}

Según Bloomberg EE. UU mostró una leve expansión en este sector, lo que indujo un mayor avance en el índice de empleo en los últimos tres años; en cuanto al Reino Unido la industria manufacturera tuvo una expansión en diciembre de acuerdo al informe de Markit Economics y el Instituto de Colegiado de Compras y Abastecimiento en Londres, sin embargo la industria disminuyó al cierre del 2012; En China también se presentó crecimiento en este sector convirtiéndose en la segunda mejor economía del mundo; Guatemala de acuerdo con las cifras del PIB creció en el 2012 en 3.1\%, en el sector manufacturero la participación del PIB fue del $17.8 \%$ constituyéndose en el sector más importante.

\section{Sector manufacturero colombiano: IED - ETN}

El Departamento de Estadística en Colombia la industria se define como la "transformación mecánica o química de sustancias orgánicas e inorgánicas en productos nuevos,

Este sector se localiza el 28\% de las ETN que hay en el país, concentrándose principalmente en los subsectores de textiles, cuero y calzado (7\%) y alimentos y bebidas (4\%) (Ramírez y Silverman, 2007, su estructura productiva, la cual sirve para determinar los impactos que genera la entrada de empresas extranjeras en el sector. Según Cárdenas (2009, "la evolución de la estructura productiva a través del tiempo es de interés, muestra cómo la disponibilidad de recursos naturales y mano de obra, lo mismo que las decisiones empresariales y gubernamentales, pueden estimular ciertas actividades y frenar otras", por lo que se puede afirmar que la presencia de la IED bajo esta modalidad influye y determina el progreso o estancamiento del sector.

\section{IED - Empresas transnacionales en el contexto de la industria manufacturera}

La Inversión Extranjera Directa ha tenido gran importancia en los países subdesarrollados y para las Empresas Transnacionales (ETN), ya que se asume que esta es parte fundamental para generar crecimiento en un país

\section{La integración MEXICO-UEA y el sector manufacturero}

El tratado de libre comercio de América del Norte (TLCAN) y la IED en México obtuvieron un rápido crecimiento, especialmente la proveniente de EUA. La Inversión estuvo canalizada hacia 
el sector de manufacturas y con el crecimiento en el periodo 1996-2005 estuvo ligado a las exportaciones de bienes intermedios y finales del sector manufacturero, el patrón de especialización se relacionó con la abundancia de mano de obra menos calificada en México que, conjuntamente con la cercanía geográfica, determinó una tendencia a que las empresas manufactureras se aglomeraran en la región fronteriza de México, según los autores la diferencia en las productividad y la dotación de capital humano determinó que al iniciar la década del 2000, las exportaciones, particularmente del sector maquilador, experimentaran una pérdida de mercado en la economía estadounidense en favor de países como China (Rocha, 2003) y (Mendoza, 2009).

Las exportaciones mexicanas llevaron a expandir su comercio durante la década de los 90 las exportaciones manufactureras no lograron diversificarse geográficamente, concentrándose al mercado de EE. UU, (Guzmán y Toledo, 2005).

La firma del TLCAN, las exportaciones mexicanas se elevaron 82.6\% en 1993 a 88.7\% en el 2000, año desde el cual se redujo su participación al $81.1 \%$ en el primer semestre de 2009, en consecuencia, de la fuerte caída de la demanda de exportaciones mexicanas de EUA.

Los sectores que dinamizaron las exportaciones de manufacturas fueron, la industria de productos metálicos, maquinaria y equipo, la que participaba en promedio en 1993 con $68.8 \%$ del total de las exportaciones, incluyendo la actividad maquiladora, elevándose su porcentaje a $71.6 \%$ en el primer trimestre de 2009. Al interior de este subsector las ramas de transporte y comunicaciones y productos automotores mostraron una elevada participación de 24.5 y $24.7 \%$, en 1993, reduciéndose 2009 a 40.5 y $17.7 \%$. El otro sector de importancia es de producción de aparatos eléctricos y electrónicos que representó 36.02\% de las exportaciones manufactureras en 1993 y $31.2 \%$ en el primer semestre de 2009.

La liberalización económica trajo una expansión de la producción y exportaciones manufactureras, autores han señalado que existen limitaciones del modelo de crecimiento manufacturero seguido por México. También se aprecian restricciones externas que se derivan del desequilibrio de la balanza comercial manufacturera observándose un bajo crecimiento de la inversión bruta fija (Moreno Brid, 1999); también existen problemas de disparidad del crecimiento manufacturero al nivel subsectorial y concentración de las exportaciones en pocas 
actividades manufactureras y alto nivel del coeficiente de importaciones del sector manufacturero (De María, Domínguez, Brown y Sánchez, 2009).

El sector manufacturero quedó determinado por los flujos de inversión extranjera directa, este flujo de recursos y tecnología se convirtió en otro mecanismo para profundizar la integración del ciclo de las manufacturas mexicanas al comportamiento del sector manufacturero de los EUA, respecto a los flujos de IED se destaca una rápida expansión en la década de los 90 representando el $66.1 \%$.

A partir del 2000 se aprecia un declive de la participación de los flujos de IED en el sector manufacturero de la economía mexicana en el total de captación de IED, cayendo $55.3 \%$ en el 2000, esta se deterioró con la recesión internacional y en 2001 y 2002 se experimentaron caídas de esa participación hasta llegar a $19.8 \%$ y $37.1 \%$, respectivamente. Finalmente se destaca que después de un repunte en 2004, el porcentaje de la IED en el sector manufacturero volvió a caer en 2007 y 2008. Finalmente, en lo relacionado al origen de la IED, se observa que EUA sigue siendo la fuente más importante de esos flujos financieros, aunque es conveniente destacar que la proporción de la inversión extranjera directa de EUA respecto al total de la IED se ha reducido considerablemente entre el año de 2001, en que presentó el mayor porcentaje respecto al total (71.2\%), y 2008 en que cayó su participación sensiblemente (45.7\%).

\section{La recesión económica de EUA y las manufacturas de MÉXICO}

Quien enfrento con mayor tendencia economía de EUA fue el sector manufacturero; de enero de 2008 a abril de 2009, cayó al 16.5\%, mientras que el crecimiento del empleo manufacturero en México cayó 9.4\%. a 6, se observa que el alto grado de sincronización del ciclo económico de estos sectores en ambos países ha determinado un alto grado de dependencia del comportamiento del sector manufactureras de México con respecto a la evolución de la producción manufacturera en EUA. 


\section{Cuadro Nro. 4}

Evolución de la Inversión Extranjera Directa en el Sector

\begin{tabular}{|c|c|c|}
\hline & $\begin{array}{c}\text { Mnversión } \\
\text { Extranjera }\end{array}$ & $\begin{array}{c}\text { Inversión Extranjera Directa } \\
\text { en el sector manufacturero } \\
\text { como porcentaje del total }\end{array}$ \\
\hline Periodo & Total & de la IED \\
\hline 1994 & $\$ 10,646.9$ & $58.16 \%$ \\
\hline 1995 & $\$ 8,374.6$ & $61.41 \%$ \\
\hline 1996 & $\$ 7,847.9$ & $60.03 \%$ \\
\hline 1997 & $\$ 12,145.6$ & $59.83 \%$ \\
\hline 1998 & $\$ 8,373 \cdot 5$ & $66.11 \%$ \\
\hline 1999 & $\$ 13,858.6$ & $55.32 \%$ \\
\hline 2000 & $\$ 18,019.6$ & $19.82 \%$ \\
\hline 2001 & $\$ 29,817.7$ & $37.07 \%$ \\
\hline 2002 & $\$ 23,728.9$ & $46.91 \%$ \\
\hline 2003 & $\$ 16,521.6$ & $55.77 \%$ \\
\hline 2004 & $\$ 23,681.1$ & $50.21 \%$ \\
\hline 2005 & $\$ 21,976.8$ & $50.85 \%$ \\
\hline 2006 & $\$ 19,428.0$ & $44.28 \%$ \\
\hline 2007 & $\$ 27,528.1$ & $29.04 \%$ \\
\hline 2008 & $\$ 22,481.2$ & \\
\hline & & \\
\hline
\end{tabular}

Fuente: Estimaciones propias con datos elaborados por la Secretaría de Economía. Dirección General de Inversión Extranjera publicados en el Banco de Información Económica de INEGI.

\section{Cuadro Nro. 5}

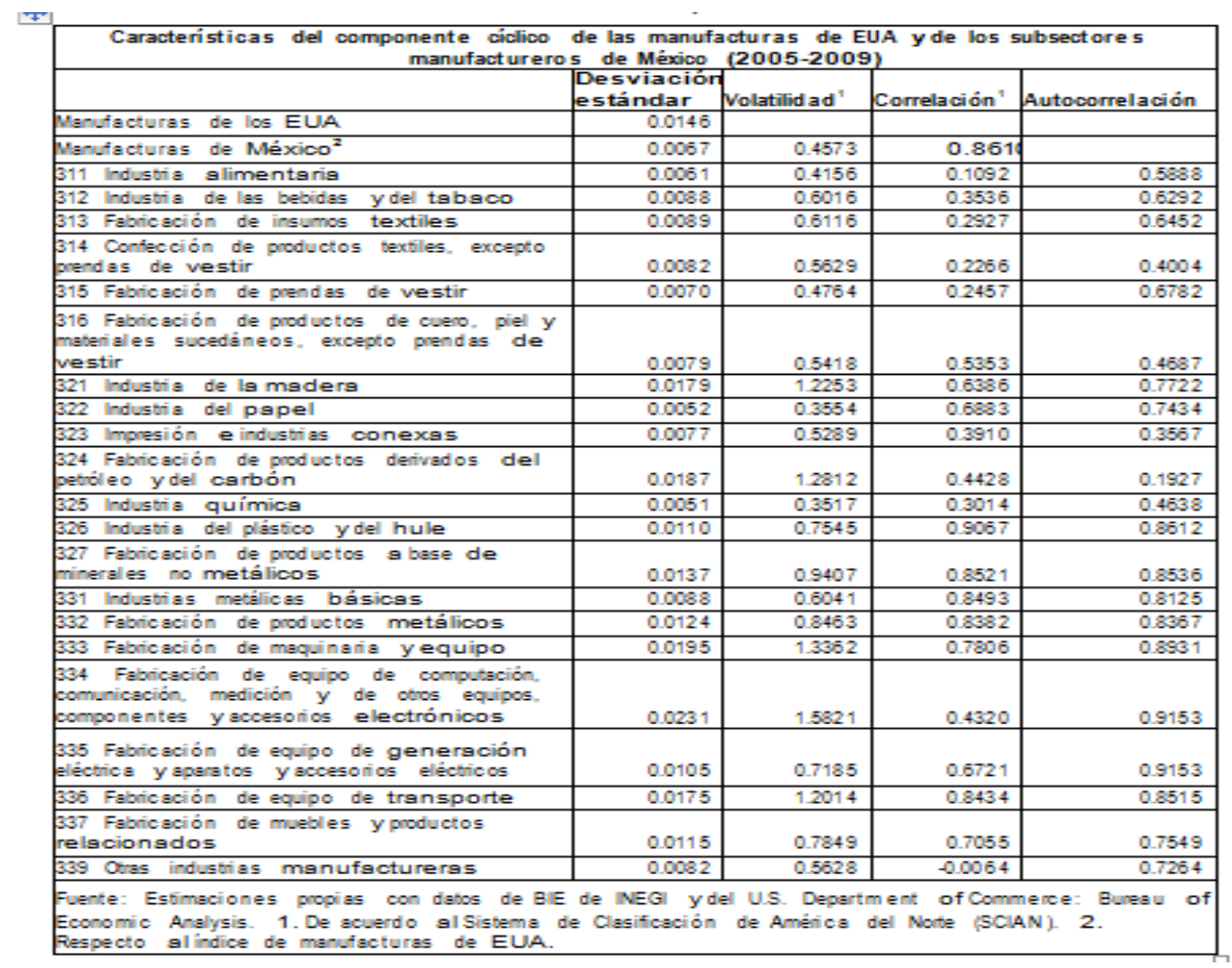




\section{Cuadro Nro. 6}

\begin{tabular}{|c|c|c|c|c|c|c|}
\hline \multicolumn{7}{|c|}{$\begin{array}{l}\text { Los cinco subsectores de la industria manufacturera mexicana con mayores } \\
\text { caídas en sus tasas de crecimiento anual entre } 2008 \text { y } 2009 \text {, de acuerdo al } \\
\text { SCIAN }\end{array}$} \\
\hline Periodo & 2005 & 2006 & 2007 & 2008 & 2009 & $\begin{array}{l}\text { Acumulado } \\
2008- \\
2009^{1}\end{array}$ \\
\hline $\begin{array}{l}336 \text { Fabricación de equipo de } \\
\text { transporte }\end{array}$ & $5.64 \%$ & $4.38 \%$ & $0.09 \%$ & $-13.64 \%$ & $-6.77 \%$ & $-20.41 \%$ \\
\hline $\begin{array}{l}334 \text { Fabricación de equipo de } \\
\text { computación, comunicación, } \\
\text { medición y de otros equipos, } \\
\text { componentes y accesorios } \\
\text { electrónicos }\end{array}$ & $0.54 \%$ & $-0.73 \%$ & $4.87 \%$ & $-7.84 \%$ & $-4.67 \%$ & $2 \%$ \\
\hline $\begin{array}{l}337 \text { Fabricación de muebles y } \\
\text { productos relacionados }\end{array}$ & $3.78 \%$ & $1.50 \%$ & $1 \%$ & $\%$ & $5 \%$ & $5 \%$ \\
\hline $\begin{array}{l}314 \text { Confección de productos } \\
\text { textiles, excepto prendas de } \\
\text { vestir }\end{array}$ & $0.10 \%$ & $1.43 \%$ & $-4.20 \%$ & $-8.80 \%$ & $-0.99 \%$ & $-9.79 \%$ \\
\hline $\begin{array}{l}313 \text { Fabricación de insumos } \\
\text { textiles }\end{array}$ & $1.49 \%$ & $-1.74 \%$ & $-6.85 \%$ & $-7.92 \%$ & $-1.25 \%$ & $-9.17 \%$ \\
\hline $\begin{array}{l}315 \text { Fabricación de prendas de } \\
\text { vestir }\end{array}$ & $3.92 \%$ & $0.55 \%$ & $-1.57 \%$ & $-7.22 \%$ & $-1.95 \%$ & $-9.16 \%$ \\
\hline
\end{tabular}

Cuadro Nro. 7

\begin{tabular}{|c|c|c|c|c|c|c|c|c|c|c|c|c|c|c|c|}
\hline Fentodo & 2000 & $\begin{array}{l}200 \\
0 / 2\end{array}$ & 2008 & $\begin{array}{l}200 \\
3014\end{array}$ & $\begin{array}{l}200 \\
3 / 5 \\
0.15\end{array}$ & $\begin{array}{l}200 \\
\text { and }\end{array}$ & $\begin{array}{l}200 \\
a / 7\end{array}$ & $\begin{array}{l}200 \\
a / 8\end{array}$ & $\begin{array}{l}200 \\
0 / 9\end{array}$ & 2008 & 20008 & 2000 & 2009 & 2009 & $\begin{array}{l}\text { Acumulado } \\
\text { en el } \\
\text { petilodo }\end{array}$ \\
\hline $\begin{array}{l}\text { Coshulla de } \\
\text { Zergora }\end{array}$ & $\begin{array}{r}7.74 \\
96 \\
\end{array}$ & $\begin{array}{l}12 \\
295\end{array}$ & $\begin{array}{r}4.62 \\
9 \% \\
\end{array}$ & $\begin{array}{l}0: \\
995\end{array}$ & $\begin{array}{l}0=2 \\
0 \% 5\end{array}$ & $\begin{array}{r}0.35 \\
95 \\
\end{array}$ & $\begin{array}{r}9.49^{-} \\
96\end{array}$ & \begin{tabular}{r|}
17.3 \\
$39 \%$ \\
\end{tabular} & $\begin{array}{r}30 . \overline{3} \\
596\end{array}$ & $\begin{array}{r}0.07 \\
96 \\
\end{array}$ & $\begin{array}{r}9.62 \\
95 \\
\end{array}$ & $\begin{array}{r}120^{\circ} \\
5 \% \\
\end{array}$ & $\begin{array}{r}10 z \\
296 \\
\end{array}$ & $\begin{array}{r}17.3 \\
5 \% \\
\end{array}$ & $-34: 229 \%$ \\
\hline comuanua & 4.53 & $\begin{array}{l}5.0 \\
2 \%\end{array}$ & $a . a a^{\circ}$ & $\begin{array}{l}6.5 \\
9 \%\end{array}$ & $\begin{array}{c}-1 \\
0.1 \\
29\end{array}$ & $\underset{0.93}{0.93}$ & $a .73$ & $\begin{array}{r}5.69 \\
95\end{array}$ & 4.09 & $\underset{95}{7.95}$ & 9.09 & $7.80^{-}$ & 9.56 & $=45^{\circ}$ & $-24.019 \%$ \\
\hline Es:a & $\begin{array}{r}1.38 \\
96 \\
\end{array}$ & $\begin{array}{l}0.7 \\
296\end{array}$ & $3.32^{\circ}$ & $\begin{array}{l}5.3 \\
396\end{array}$ & $\begin{array}{l}1.0 \\
495 \\
\end{array}$ & 329 & $\begin{array}{r}4.11 \\
96 \\
\end{array}$ & $\begin{array}{r}=.10^{-} \\
\%\end{array}$ & $\begin{array}{l}228 \\
96\end{array}$ & $\begin{array}{r}2.74 \\
95\end{array}$ & $\begin{array}{r}13.99 \\
96\end{array}$ & $\begin{array}{r}3.14^{-} \\
95 \\
\end{array}$ & $\begin{array}{r}7 \times 3 \\
96\end{array}$ & $\begin{array}{r}50.0 \\
96\end{array}$ & $-20.539 \%$ \\
\hline $\begin{array}{l}\text { Eala } \\
\text { colsomla } \\
\text { aur }\end{array}$ & $\begin{array}{r}10 . \overline{-} \\
295\end{array}$ & $\begin{array}{l}0.7 \\
195\end{array}$ & $=9 \mathrm{ss}$ & $\begin{array}{l}9.4 \\
295\end{array}$ & $\begin{array}{l}7.6 \\
495\end{array}$ & 5.97 & $\begin{array}{r}2.73 \\
96\end{array}$ & $\begin{array}{r}4.75 \\
95\end{array}$ & $\underset{95}{4.95}$ & $\begin{array}{c}13.7 \\
395\end{array}$ & 9.82 & $\begin{array}{r}7.81 \\
95\end{array}$ & $\begin{array}{r}0.41 \\
96\end{array}$ & 5.98 & $-15.23 \%$ \\
\hline Thexceale & $\begin{array}{r}1.47 \\
96\end{array}$ & $\begin{array}{l}3.9 \\
6 \% 5\end{array}$ & $\begin{array}{r}1.75 \\
95\end{array}$ & 0.9 & $4:=$ & 1.87 & 0.57 & $\begin{array}{r}2.25 \\
95\end{array}$ & 1.07 & $\begin{aligned} 2.48 \\
\% 5\end{aligned}$ & $7-12$ & $\begin{array}{r}11.8 \\
395\end{array}$ & $\begin{array}{r}1.38 \\
95\end{array}$ & $=7 \overline{3}$ & -13.589 \\
\hline aomora & $\begin{array}{r}7.57 \\
96 \\
\end{array}$ & $\begin{array}{l}5.8 \\
0 \% 5\end{array}$ & $\begin{array}{r}4.23 \\
96\end{array}$ & $\begin{array}{l}6: 2 \\
196\end{array}$ & $\begin{array}{l}7.5 \\
5 \% \\
\end{array}$ & $\begin{array}{r}1.65 \\
96 \\
\end{array}$ & $\begin{array}{r}a .64^{-} \\
9 \mathrm{~s}\end{array}$ & $\begin{array}{r}a .98 \\
96\end{array}$ & $\begin{array}{r}3.58 \\
95\end{array}$ & $\begin{array}{c}132 \\
295 \\
\end{array}$ & $\begin{array}{r}14.59 \\
96 \\
\end{array}$ & $\begin{array}{r}3.01 \\
95 \\
\end{array}$ & $\begin{array}{r}34.4 \\
195 \\
\end{array}$ & $\begin{array}{r}10.1 \\
39 \% \\
\end{array}$ & -4.7296 \\
\hline Noyerts & $\begin{array}{r}7.30 \\
96\end{array}$ & $\begin{array}{l}13.5 \\
15 \\
96\end{array}$ & $\begin{array}{r}2.88 \\
96\end{array}$ & $\begin{array}{l}1.8 \\
8 \%\end{array}$ & $\begin{array}{l}1.3 \\
5 \% \\
\end{array}$ & $\begin{array}{r}25.4 \\
59 \%\end{array}$ & $\begin{array}{r}6.15 \\
.5\end{array}$ & $\begin{array}{r}6.93^{-} \\
95^{-1}\end{array}$ & 0.28 & $\begin{array}{r}2.43 \\
\% \mathrm{~s}\end{array}$ & $\begin{array}{r}3.24 \\
95\end{array}$ & $\begin{array}{l}30.7 \\
5 \% 5\end{array}$ & $\begin{array}{c}0.98 \\
95\end{array}$ & $\begin{array}{r}14.8 \\
69 \%\end{array}$ & 28.1796 \\
\hline $\begin{array}{l}\text { veracina de } \\
\text { langelo de is } \\
\text { wave }\end{array}$ & $\begin{array}{r}19.8 \\
895 \\
\end{array}$ & $\begin{array}{l}\text { a.7. } \\
996\end{array}$ & $\begin{array}{r}9.91 \\
95\end{array}$ & $\begin{array}{l}0.9 \\
5 \%\end{array}$ & $\begin{array}{l}3.4 \\
296 \\
\end{array}$ & $\begin{array}{r}6.48 \\
9 \%\end{array}$ & $\begin{array}{r}0.25 \\
96 \\
\end{array}$ & $\begin{array}{r}9.17 \\
9 \% \\
\end{array}$ & $\begin{array}{r}1.30 \\
\$ \%\end{array}$ & $\begin{array}{r}9.27 \\
95 \\
\end{array}$ & $\begin{array}{r}7.38 \\
95 \\
\end{array}$ & $\begin{array}{r}4.31 \\
95 \\
\end{array}$ & $\begin{array}{r}242 \\
195 \\
\end{array}$ & $\begin{array}{r}127 \\
69 \% \\
\end{array}$ & 11.8996 \\
\hline Comoeche & $\begin{array}{r}14.7 \\
796\end{array}$ & $\begin{array}{l}2.1 \\
0.1\end{array}$ & $\begin{array}{r}9.47 \\
96\end{array}$ & $\begin{array}{l}15 \\
6 \%\end{array}$ & $\begin{array}{l}2.5 \\
29\end{array}$ & 9.49 & $\begin{array}{r}1.9 \mathrm{a}^{-} \\
9 \mathrm{~s}\end{array}$ & $\begin{array}{r}3.14 \\
95\end{array}$ & $\begin{array}{r}3.55 \\
95\end{array}$ & $\begin{array}{r}2.13 \\
95\end{array}$ & $\begin{array}{r}6.35 \\
95\end{array}$ & $\begin{array}{r}0.40^{-} \\
95\end{array}$ & $\begin{array}{r}4.12 \\
96 \\
\end{array}$ & $\begin{array}{r}7-17 \\
9 \%\end{array}$ & $14.239 \%$ \\
\hline Oaxaca & $\underset{96}{4.48}$ & $\begin{array}{c}14 . \\
68 \\
95\end{array}$ & $\begin{array}{l}2 a .1 \\
29\end{array}$ & 1.3 & $\begin{array}{l}5.1 \\
5 \%\end{array}$ & $=8$. & 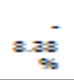 & $\begin{array}{r}2.60 \\
9 \%\end{array}$ & 18.8 & $\begin{array}{r}19.8 \\
19 \% \\
\end{array}$ & $\begin{array}{c}1.11 \\
95\end{array}$ & $\begin{array}{r}7.41 \\
95\end{array}$ & $=8.84^{-1}$ & $9.00^{\circ}$ & $6.38 \%$ \\
\hline Colsoss & $\begin{array}{r}4.04 \\
96 \\
\end{array}$ & $\begin{array}{l}6.1 \\
296\end{array}$ & $\begin{array}{r}3.07 \\
9 \%\end{array}$ & $\begin{array}{l}29 \\
796\end{array}$ & $\begin{array}{l}52 \\
096\end{array}$ & 9.37 & $\begin{array}{r}1.0- \\
96 \\
\end{array}$ & $\begin{array}{r}2.65 \\
96\end{array}$ & $\begin{array}{r}1.47 \\
96 \\
\end{array}$ & $\begin{array}{r}3.51 \\
96 \\
\end{array}$ & $\begin{array}{r}10.74 \\
95 \\
\end{array}$ & $\begin{array}{r}2.40 \\
96\end{array}$ & $\begin{array}{r}5.35 \\
96 \\
\end{array}$ & $\begin{array}{r}6.04^{-1} \\
9 \%\end{array}$ & $1.90 \%$ \\
\hline Oulntans & $\underset{95}{0.45}$ & 0.8 & 3.94 & $\begin{array}{l}3.4 \\
695\end{array}$ & 5.7 & 6.04 & $\underset{95}{0.95}$ & $\begin{array}{l}1.3 a \\
9 \mathrm{~s}\end{array}$ & $=0.7$ & $\begin{array}{r}4.84 \\
9 \mathrm{~s}\end{array}$ & $\begin{array}{r}3.40 \\
95\end{array}$ & $\begin{array}{r}5.54 \\
95\end{array}$ & 0.39 & $=00^{\circ}$ & $1.75 \%$ \\
\hline
\end{tabular}




\section{EI Documento “El Desarrollo de la Industria Manufactura y el Desarrollo Sustentable,}

\section{Chile}

Chile durante 1990-2000, el sector manufacturero obtuvo un crecimiento promedio anual de 5\%, inferior al 6\% arrojado por la economía nacional, lo que conlleva a una disminución en su contribución al PIB nacional, la que pasó de un 18.7\% en 1990 a un $16.1 \%$ en el año 2000. Se observa una pérdida de la importancia relativa del sector industrial en la generación del producto, perdiendo fuerza en la economía nacional, las ventas externas de la industria manufacturera durante el período bajo análisis crecieron a un ritmo anual promedio de $11.6 \%$, posicionándolo como el sector líder del comercio exterior chileno, aportando el $46 \%$ de las exportaciones del año 2000, se deduce que el crecimiento del sector industrial ha sido más bien gracias a la producción del subsector orientado a satisfacer la demanda externa más que al consumo doméstico; en términos de empleo, el sector manufacturero absorbe actualmente el 14.3\%, dando cuenta de un crecimiento promedio anual en su empleo de $0.2 \%$ en la última década, bastante inferior al $1.7 \%$ arrojado por la economía nacional. Cabe señalar que sólo el $26.6 \%$ de la mano de obra ocupada en la industria manufacturera en 1996 era de sexo femenino mientras que a nivel nacional la participación de la mujer en el empleo era de 32\% (García Huidobro y Wurgaft, 1999).

\section{Cuadro Nro. 8}

\begin{tabular}{|c|c|c|}
\hline Códino & Rama & $\underset{(96)}{\text { Contribución }}$ \\
\hline $\begin{array}{l}300 \\
311\end{array}$ & $\begin{array}{l}\text { Total Manufactura } \\
\text { Fobricac. de productos alimenticios }\end{array}$ & $\begin{array}{r}100 \\
22.4\end{array}$ \\
\hline 313 & Industrias de bebidas & 4.3 \\
\hline 314 & Industria del tabaco & 3.7 \\
\hline 321 & Fabricac de textiles & 5.1 \\
\hline 322 & Fabricac. prendas de vestir, excepto calzado & 2.5 \\
\hline 323 & $\begin{array}{l}\text { Industria del cuero: produc. decuero y } \\
\text { sucedáneos }\end{array}$ & 0.5 \\
\hline 324 & Fabricac. de calzado, exc. de cauchoo plástico & 1.7 \\
\hline 331 & $\begin{array}{l}\text { Industria de madera y sus productosexc. } \\
\text { muebles }\end{array}$ & 4.0 \\
\hline 332 & Fabricac. de muebles y acoesorios, exc. & 0.9 \\
\hline 341 & $\begin{array}{l}\text { metalicos } \\
\text { Fabricac. de papel y productos de papel }\end{array}$ & 7.9 \\
\hline 342 & Imprentas, editorialese industrias conexss & 3.1 \\
\hline 351 & Fabricac. de sustancias químicas industriales & 4.7 \\
\hline 352 & Fabricac. de otros productos químicos & 7.3 \\
\hline 353 & Refinerías de petróleo & 6.3 \\
\hline 354 & Fabricac. prod. derivadas de petróleo y carbón & 1.4 \\
\hline 355 & Fabricac. de productos de caucho & 1.0 \\
\hline 356 & Fabricac. de productosplásticos nep & 2.2 \\
\hline 361 & Fabricac. de objetos de loza y porcelans & 0.3 \\
\hline 362 & Fabricac. de vidrio y productos de vidrio & 0.7 \\
\hline 369 & Fabricac. otros productos minerales no metálicos & 2.6 \\
\hline 371 & Industrias básicas de hierro y acero & 5.1 \\
\hline 372 & Industrias básicas de metales no ferrosos $2 /$ & 1.6 \\
\hline 381 & $\begin{array}{l}\text { Fabricac. prod. metálicos exc. maquinaria y } \\
\text { equipo }\end{array}$ & 5.0 \\
\hline 382 & Construcción de maquinsria, exc. la eléctrica & 2.5 \\
\hline 383 & Construcción máq.. aparatos y acoes. eléctricos & 1.6 \\
\hline 384 & Construcción de material de transporte & 1.3 \\
\hline 385 & $\begin{array}{l}\text { Fabricac. equipo profesional y artículos } \\
\text { oftélmicos }\end{array}$ & 0.2 \\
\hline
\end{tabular}

Como se desprende de la tabla anterior, el sector manufacturero es altamente intensivo en el uso de recursos naturales, específicamente, de los sectores pesquero, forestal, 
El sector manufacturero es intensivo en el uso de recursos naturales como el pesquero, forestal, agrícola y minero, generando productos de bajo valor agregado, es mucho más marcado en el caso de las exportaciones industriales; de acuerdo a Alarcón y Stumpo (2000) "el nuevo perfil productivo adquirido por el sector manufacturero chileno en los últimos 20 años son las plantas procesadoras de celulosa, harina de pescado, conservas, alimentos congelados, etc.

El valor agregado per cápita del sector manufacturero (MVA per cápita) ha tenido un crecimiento significativo, en los ochenta con un valor muy por debajo al resto de los países latinoamericanos, hasta llegar a niveles incluso superiores al promedio de la región a fines de la década de los noventa, y manteniendo un valor siempre muy superior al promedio de los países en desarrollo (2.2 veces en 1998), sin embargo, al comparar el MVA per cápita de la industria manufacturera chilena con el de los países desarrollados, se advierte una gran brecha, reflejado en un valor para este indicador en dichos países para 1998 unas 7.6 veces superior al chileno.

\section{Cuadro Nro. 9}

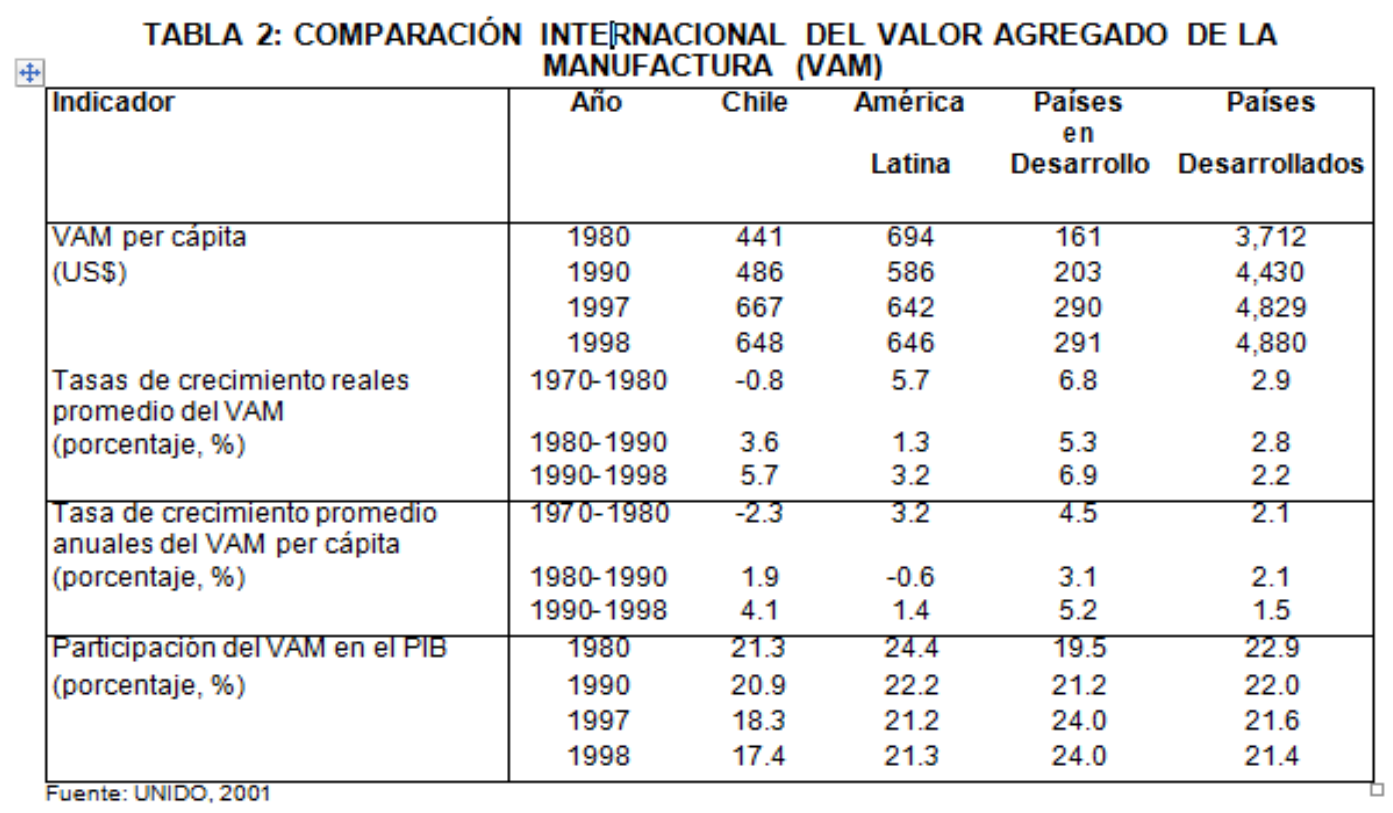

\section{Discusión}

La CEPAL en su artículo sobre Reestructuración industrial y competitividad internacional en América Latina y el Caribe (CAN 97/025), visualiza los cambios estructurales, comparación de taxonomías y la evolución de la estructura industrial. 
Se analiza la Evolución de la Estructura de la Industria Manufacturera, desde una visión mundial hasta ubicarse en Latinoamérica, con países que han aportado significativamente al crecimiento industrial, considerando varios documentos que reflejan el avance económico en el periodo analizado.

La industria Manufacturera se establece primero el cambio estructural desde los años setenta; segundo se comparan las taxonomías de sectores de la industria para verificar las de mayor intensidad de conocimientos; tercero se analiza la evolución de la estructura industrial de algunos países entre 1970 y 2003, dividiéndose en etapas como la de crecimiento con endeudamiento, años setenta, década perdidas años 1980, retorno de capitales externos en los noventa y el ciclo moderado de crecimiento que se inicia con el siglo XXI.

Bajo el sistema de Bretton Woods se determina las siguientes fases: 1970-1973, marca el fin del período áureo de crecimiento de la economía y el comercio internacionales, que se inició a comienzos de los años sesenta; la segunda, que transcurre entre 1974 y 1981; La tercera fase, 1982-1990; y la cuarta fase comprende los años entre 1991 y 2000.

LA OCDE y la CEPAL dentro de Latinoamérica identifican tres grupos de países: Los de Cono Sur concentrados en bienes primarios y manufacturas basadas en recursos naturales; Centro América Especializados en la exportación de manufacturas de mediana y baja tecnología derivadas de la industria manufacturera de exportación; Grupo conformado por Costa Rica, Brasil y México que presentan el mayor grado de diversificación regional en las exportaciones incluyendo manufacturas de mediana y alta tecnología.

Crédito Bruto Industria Manufacturera Guatemala, informe trimestral bancos: Q 15,001.5 millones diciembre de 2012; Crecimiento 16.2 \% en relación al año anterior; Participación de la Cartera de Créditos $11.9 \%$; y, productos.

1. Alimenticios, bebidas y tabacos; Q 1,417.5 millones (16\%)

2. Metálicos, maquinaria y equipos Q230.4millones; industrias metálicas Q181.6 millones

3. Textiles, prendas de vestir e industrias de cuero Q 115.6 millos

4. Minerales no metálicos exceptuando derivados del petróleo y del carbón Q 115.6 millones

La Evolución de la inversión extranjera directa en el sector Manufacturero de México, 1994 2008 en su conjunto parecen haber caído relativamente menos drástica que la de EUA, al analizar los subsectores. 
La Industria Manufacturera Chilena 0990 - 2000 experimento un crecimiento promedio anual de $5 \%$, el PIB disminuyo de $18.7 \%$ en 1990 a $16.1 \%$ en el 2000 , esto influyo en la economía del país., las ventas externas de la industria manufacturera durante el período bajo análisis crecieron a un ritmo anual promedio de $11.6 \%$, posicionándolo como el sector líder del comercio exterior chileno, aportando el $46 \%$ de las exportaciones del año 2000.

\section{Conclusiones}

El presente artículo permitió evidenciar algunas caracterizaciones de la inversión extranjera en el sector manufacturero de América Latina y el Caribe; evidencia el desarrollo productivo en la industria Manufacturera y crecimiento económico de acuerdo al artículo de la edición del Proyecto CEPAL; se conoce la evolución de la estructura he la Industria Manufacturera de la CEPAL según (PADIWIN). Bajo el sistema de BRETTON WOODS; LA OCDE Y LA CEPAL identifican tres grupos de países como son los del Cono Sur, Centro América y los conformados por Costa Rica, Brasil y México; la Industria Manufacturero de Guatemala 2002 - 2012, se conoce su crecimiento porcentual, su participación en la cartera de créditos y los productos fabricados de acuerdo al sector los mismos que representaron el 18.3\% del PIB en el último trimestre; el porcentaje de participación de Colombia, la industria manufacturera la misma que ha mantenido leves fluctuaciones su participación nunca fue mayor al $22.7 \%$ dentro del PIB. Cifra reportada para el año 1995, para 1999 por el endeudamiento el PIB bajo al 6.1 \%; el sector Manufacturero de México juega un papel importante en las relaciones económicas entre Estados Unidos y México; la industria Manufacturera de Chile experimento un crecimiento anual del 5\% y el PIB disminuyo de $18.7 \%$ en 1990 a un $16.1 \%$ en el 2000; cuando hablamos de inversión extranjera directa en los sectores Manufactureros los inversionistas buscan invertir en países que tengan un sistema político estable y seguro, evitan invertir en regiones con una alta inestabilidad política donde pueden correr el riesgo de ser expropiados; es de gran importancia la acción del gobierno particularmente en economías de bajos ingresos destinada a atraer y regular la IED de forma que genere innovación y efectos de derrame tecnológico, que sea incluyente desde una perspectiva socioeconómica y sostenible en términos ambientales. 


\section{Referencias Bibliográficas}

ADLAS, J. y L. Achoth (2006), "Is the green revolution vanishing? Empirical evidence from TFP analysis for rice", documento presentado en la Conferencia de la International Association of Agricultural Economics (IAAE), Gold Coast, Australia.

AMAR K.J. R. Nayak (2008) Multinationals in India: FDI and Complementation Strategy in a

Developing Country. Palgrave Macmillan

BANCO Mundial, (2010), World Development Indicators - CDR.

CEPAL (2011). La inversión extranjera directa en América Latina y el Caribe

CEPAL (2012). La inversión Extranjera directa en Latino América y el Caribe

CHUHAN, P., G. Pérez-Quiroz y H. Popper (1996). "International Capital Flows: Do Shortterm Investment and Direct Investment Differ?” Policy Research Working Paper 1669. Washington, DC: World Bank. October.

La edición y publicación del proyecto CEPAL / Centro Internacional de Investigaciones para el Desarrollo (IDRC, Canadá) sobre Reestructuración industrial y competitividad internacional en América Latina y el Caribe (CAN 97/025).

DÍAZ VÁZQUEZ, R. (2002): "Un estudio descriptivo de la inversión extranjera directa en España y su distribución territorial

DUNNING, John H. (1997). "Re-evaluating the Benefits of Foreign Direct Investment" en Alliance capitalism and global business. Studies in International Business and the World Economy, vol. 7. London and New York: Routledge, 1997, pp. 209-34.

ESTUDILLO, J.P. y K. Otsuka (2006), "Lessons from Three Decades of Green Revolution in the Phillippines", Foundation for Advanced Studies on International Development (FASID), inédito.

FIGLIO, D.N.; BLONIGEN, B.A. (2000): "The Effects of Foreign Direct Investment on Local Communities", Journal of Urban Economics, núm. 48, pp. 338-363.

GAEZ (Zonas Agro-Ecológicas Mundiales) (2013), “Zonas Agro-Ecológicas mundiales”, Mapa:

Relación del rendimiento real y potencial de los principales cultivos

MORALES. Josefina (2010). Revista problemas del desarrollo,163(41)

MORISSET, Jacques y Neda Pirnia (2000) "How Tax Policy and Incentives affect Foreign Direct Investment" World Bank Working Paper (No 2509). 
PINGALI, P. (2007), "Will the Gene Revolution Reach the Poor? - Lessons from the Green Revolution”, document presentado en la VII Conferencia Manshold, Wageningen, enero.

ROUDART. L. (2010). Origines et transformations d'un systémes hydroagricoles

TOBAR, M. Paulina (2011). Superintendencia de bancos y seguros del Ecuador Inversión extranjera directa y su impacto en el sistema financiero nacional.

UNITED NATIONS (2011), UNCTAD STAT

UNCTAD (Conferencia de las Naciones Unidas sobre Comercio y Desarrollo) (2012), Informe sobre Inversiones en el Mundo (UNCTAD/WIR/2012), Ginebra

Martine Dirven, Hubert Escaith, João Carlos Ferraz, Soledad Parada, Wilson Pérez, Gabriel Porcile, Annalisa Primi, Mônica

Rodríguez, Sebastián Rovira, Marcia Tavares y Sebastián Vergara.

La edición y publicación de este documento fue posible gracias al apoyo financiero del proyecto CEPAL / Centro Internacional de Investigaciones para el Desarrollo (IDRC, Canadá) sobre Reestructuración industrial y competitividad internacional en América Latina y el Caribe (CAN 97/025).

Las opiniones expresadas en este documento, que no ha sido sometido a revisión editorial, son de exclusiva responsabilidad de los autores y pueden no coincidir con las de la Organización.

Publicación de las Naciones Unidas

LC/W.136

Copyright (C Naciones Unidas, octubre de 2007. Todos los derechos reservados Impreso en Naciones Unidas, Santiago de Chile

REVISTA DE LA CEPAL 75 • DICIEMBRE 2001. PRODUCTIVIDAD Y COMPETITIVIDAD INTERNACIONAL • JORGE KATZ Y GIOVANNI STUMPO.

Hatzichronoglou, T. (1997), "Revision of the High-. Technology Sector and Product Classification", OECD. Science, Technology and ...

Pavitt'S Taxonomy Sixteen Years On: A Review Article (Fajnzylber, 1990), (PADIWIN) de la CEPAL

United Nations industrial Depelopment Organization - UNIDO 